\title{
Twist and Shape: Feedback Practices within Creative Subject Content of Hairdressing Education
}

\author{
Anna Öhman ${ }^{1}$ \\ Received: 31 December 2016 / Accepted: 11 December 2017 / \\ Published online: 8 January 2018 \\ (C) The Author(s) 2018. This article is an open access publication
}

\begin{abstract}
The aim of this study is to explore feedback practices and how such actions of assessment emerge from embodied participation in classroom interactions between teachers and students. Using video recordings of teacher and student interactions in hairdressing education, I look at how feedback practices within creative subject content are produced between the participants as social actions situated in interaction, using conversation analysis. Feedback is contingent upon an embodied moment-to-moment monitoring and collaboration between the teacher and student, and is organized as a trajectory from problem detection through exploration until a final solution is found. Feedback within creative subject content is displayed as a multifarious exploration of embodied as well as materially situated professional knowledge. Overall, the findings show how feedback is mutually produced in a process, making tacit dimensions of hairdressers' knowing explicit. This allows for improving the quality of the work over time in a trajectory of problem solving phases gradually displaying how to assess creative subject content of the material product worked on.
\end{abstract}

Keywords Feedback - Assessment - Creative subject content - Vocational education . Participation $\cdot$ Conversation analysis

This article explores feedback practices within ongoing teaching in hairdressing education in Sweden, with a special interest in how feedback is organized as part of a creative process. The study is an empirically based contribution to research on assessment in classroom interaction that understands feedback as situated activities in social interaction (Merry et al. 2013). Studying this kind of educational activity, where the student is training on a mannequin head simultaneously to getting instructions and being assessed by the teacher, displays feedback as a social practice in a moment-by-

Anna Öhman

anna.ohman@kau.se

1 Department of Educational Studies, Karlstad University, 65188 Karlstad, Sweden 
moment student-teacher interaction related to available resources in the environment (Goodwin and Goodwin 1992; Goodwin 1994). As direct evidence derived from observations of interactive classroom dialogue in studies of feedback is scant (Black 2015), not least in vocational education (Heitink et al. 2015), this study contributes with its attention paid to vocational education as a site that contains rich and multilayered feedback practices.

From video recordings of teacher-student interactions, feedback is investigated and analyzed, building upon an ethnomethodologic conversation analytic approach (henceforth EMCA) (Garfinkel 1967; Sacks et al. 1974). There are studies on the professional work of hairdressers from various theoretical approaches (e.g., Billett 1995; Chugh and Hancock 2009; Cohen 2010; Holmes 2015; Lindsay 2004; McMurtrie 2010; YeadonLee et al. 2011), although few take an ethnomethodological approach (e.g., Horlacher 2017; Oshima 2014). In the context of vocational education, research of hairdressing is also scarce (Andersson Gustafsson 2002; Öhman 2015; Öhman and Tanner 2017; Klope 2015) and feedback practices in interaction between teacher and student within creative subject content of hairdressing have not been accounted for. There is, though, a similar interest in professional vision and tacit knowing with dimensions of creativity within craftwork, in some studies from related educational programs such as floristry (Gåfvels 2016), bookbinding (Tyson 2014), textile craft (Ekström 2013) and architecture (Lymer 2013).

Hairdressing education in Sweden consists of 3 years' school-based vocational or apprenticeship education, in the handicraft programme. In addition to common upper secondary school subjects, the students study specific vocational subjects and practice in hairdressing salons. ${ }^{1}$ At the beginning of their education, the time period from which this study's material is drawn, the students work on mannequin heads, but as they get more experienced many hairdressing classes also receive clients to their school for various hair treatments. Students are thus provided with multifarious experiences. Compared with higher education, however, there is little distinction when it comes to specific concepts, procedures and dispositions that need to be learnt (Billett 2011). In order to understand the nature of vocational knowledge, it has been theorized as contextualized with regard to cognitive processes of meaning making as inferential relations between concepts and actions (Heusdens et al. 2016). This mentalistic orientation, though, may not entirely account for the socially situated embodied processes and the materiality through which the vocational knowledge is produced. In this study cognition is understood as socially distributed, jointly produced and mediated by a variety of resources, where thinking and learning take place in interaction (Hutchins 2006). As part of distributed practices, cognition is not situated exclusively within the mental life of a single individual, rather as embedded within the setting of participants and a task being performed. (Goodwin 1997, 2010). Established in the seminal study by Goodwin (1994), professional vision is a theoretical concept that concerns skilled actions in a community of more or less experienced participants, consisting of socially organized ways of seeing and understanding events: thus,

\footnotetext{
${ }^{1}$ The students have 15 weeks of workplace-based learning during their education.
} 
not vision per se, but the part played by visual phenomena in the ongoing action (Goodwin 2001). In this article, professional vision is explored in the hairdressing profession through feedback practices between teacher and student in a local educational context.

A central purpose of vocational education is to enable future professionals to become skilled in their craft and capable of understanding complex instructions and evaluations, in order to produce high quality work. Vocational education consists of assignments in socially situated activities of participation (cf. Goffman 1981; Goodwin 2000). Students encounter practical problems that raise multifaceted questions with many possible solutions or yet unknown answers. Problem solving is thus important in order to learn and use knowledge in new situations (Kilbrink and Bjurulf 2012). Solving problems is part of an explorative education allowing for mistakes, unlike workplace training (Berner 2010).

Becoming a hairdresser is a situational activity learned through participation in professional activities (Billett 2001). The education entails both relying on existing knowledge as well as being innovative to create something new. There is a fine line between teachers' 'tacit' expert knowing and 'the telling' in instructing (Sadler 2010). For the student, learning how to evaluate a product in progress is part of becoming a professional, with actions of planning and performing involving aesthetic as well as material properties. This is a multidimensional and experiential process of embodied activities with the material environment, through tactile and kinesthetic experiences intertwined with more abstract contextualized estimations of the aimed-for product to be achieved, in which the practice of higher order thinking in fulfilling non-routine problem solving is part of the profession (Billett 2011). Being creative is often associated with the vocation of hairdressing. Providing for feedback in this kind of setting poses challenges for the teacher as well as the student. The teacher evaluates the ongoing work as well as the student's performance, and the student her own work and need of support. The social organization of feedback as part of a creative process has not been the object of empirical study in a classroom setting. The aim of the study is therefore to explore feedback practices in teacher-student interaction within creative subject content in hairdressing education.

\section{Studying Feedback Practices within Creative Knowledge Domains}

In this study feedback is conceptualized as socially and interactively constructed by teacher and student (Price et al. 2013), embedded in actions of assessment, instructions and demonstrations with regard to an ongoing educational task (Öhman 2015). Typical for the craft being learned is that there are multiple and often tacit solutions to the task, which makes feedback itself embodied in the ongoing interaction within the particular practice and material environment of the profession. Feedback is thus studied as situated and embodied in an educational setting constituted through an ongoing interaction between participants working on material in a visible and tangible process (e.g., Ekström 2013; Öhman and Tanner 2017). 
The participants engage in evaluating present results as well as future possibilities of improvements. Seen as a consequence of an assessment, feedback is often a next step in instruction (Taras 2013). Assessments in EMCA are seen as social actions (Pomerantz 1984; Mondada 2009), as products of participation and knowledge claims, whereas the assessable refers to the entity being evaluated by an assessment (Goodwin and Goodwin 1987). In an institutional setting such as hairdressing education, assessments are part of an educational interaction in which the participants are orienting to the institutional purposes of the activity (Heritage 2005). In this interaction, concerns and problemsolving actions in teacher-student feedback practices have been found (Öhman 2015; Öhman and Tanner2017). Similar phenomena of problem solving and responsive actions to student displays of competence or trouble have been studied in scaffolding practices (Koole and Elbers 2014), and delivering critique or facilitating student autonomy are other aspects of feedback interaction (Skovholt 2017). How feedback is organized and accomplished within creative subject content is yet to be investigated.

Being an under-researched area, there are few empirical studies which show how creativity unfolds (Tanggaard 2014b). Creativity is often seen as individual traits or talents in people doing something entirely new, but research within the field of social psychology and educational science (Amabile 1996; Tanggaard $2014 \mathrm{a}, \mathrm{b})$ shows how creativity is a collaborative and problem-solving practice. Creativity in this approach is understood as a heuristic activity enabling immersion into subject areas and renewing existing practices through collaborative actions emanating from resistance in the materials worked on (Tanggaard 2014a). In line with this view, reproduction is an important part of the process, providing for a "we-creativity" (Tanggaard 2014b, p. 55) as well as "sociomaterialized" understanding of the concept (Tanggaard 2013). Creativity in this study is thus approached from this perspective.

Hairdressing is largely materialized and tacit in its practice including creative aspects of reproduction and renewal of aesthetics and design. Studies within handicraft education have found that aesthetic standards are of largely tacit dimensions directly related to materiality (Gåfvels 2016; Tyson 2014). Teachers' embodied actions in modelling aesthetic qualities need more work in making tacit dimensions explicit (Asplund and Kilbrink 2016). Design is also found as embedded in intentions and instructions (Lymer 2013). However, the material worked on is part of instructional processes in which the embodied interactions make understanding publicly available (Ekström and Lindwall 2014). These studies are of interest since they move beyond the conception of creativity as individualistic or divergent thinking, and approach creativity as embedded in an ongoing practice and particular field of assessable knowledge. This article sets out to broaden this research by studying how feedback within creative subject content in hairdressing education is organized. I will henceforth use the single term feedback, to represent the wording from the aim: feedback practices in teacher-student interaction within creative subject content in hairdressing education.

Within this conversation analytically informed research, human actions are seen as collaborative, participatory and embodied (Goodwin 2013). Feedback practices 
seen as participatory human actions are thus understood as local configurations of meaning that are reused or operated on to build the next action. Goodwin uses the term "lamination" (p. 12) to conceptualize how different resources are organized as meaning-making layers with reference to each other displaying connections. The concept of lamination has been used to describe layered and temporally unfolding processes in which participants demonstrate to each other their ongoing understanding of the events (Goodwin 2006). Individual utterances are embedded within sequences of dialogue with others and cannot be understood or analyzed in isolation. This approach to meaning and understanding is conceptualized as participation framework (Goodwin 2000), constructed by the participants themselves through their unfolding actions, displaying their understanding in co-ordination as well as negotiation. Participation builds on Goffman's (1981) studies of participants' alignment toward one another, including how embodied postures and the use of prosodic resources such as pitch or volume entail continual shifts in participation. Participation is thus a concept which holds both a dimension of human interaction and a perspective of analysis (Duranti 1997, p. 280), in this study used to investigate the situated activities from an interest in feedback practices in creative subject content. Finally, in this outlining of the theoretical approach, affiliation is an important concept to consider. The term describes a stance showing that you are 'with' someone, central to social life in which mitigating threats strengthens social relations to solidarity displayed in responsive actions to something a co-participant said or did, by tuning in to the specific experience of the other. Affiliation is produced with various resources such as prosody, laughter, assessments and response cries (Lindström and Sorjonen 2012), in this study analyzed as part of the intersubjective and socializing aspects of feedback practices.

\section{Data and Method}

The analysis is based on empirical material of video recorded teacher-student classroom interactions collected in 2015 in a Swedish vocational school with hairdressing education, following the teacher. The use of a handheld camera together with a head-mounted camera allows for distant as well as close views of the activities and also for capturing multiple perspectives. As the head-mounted camera is carried by the teacher, it also involves research participants in the data collection process (cf. Blikstad-Balas and Sørvik 2015; Öhman 2016). The details of participants' focus are not captured by the handheld camera but with the head-mounted camera, as shown in Fig. 1:

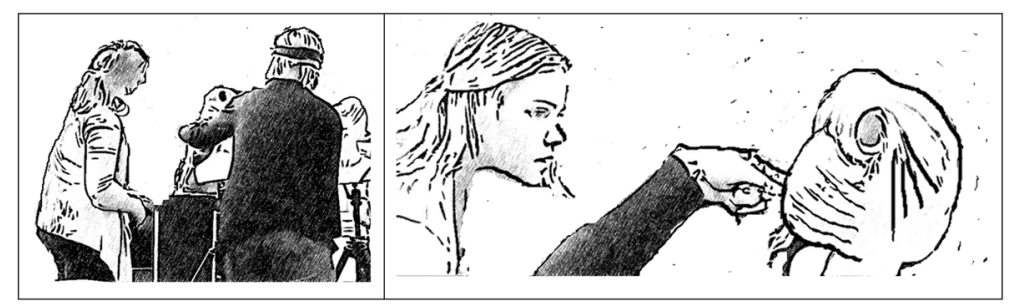

Fig. 1 Still images from simultaneous recording with handheld camera and head-mounted camera 
Table 1 Table of the data collection/video recordings

\begin{tabular}{|c|c|c|c|}
\hline \multirow[t]{2}{*}{ Days } & \multicolumn{2}{|c|}{ Time in minutes $/ \mathrm{h}$} & \multirow[t]{2}{*}{ Lesson content } \\
\hline & Handcam & Headcam & \\
\hline September 7 & $234 / 3,9$ & $114 / 1,9$ & Cutting, tools and graphics \\
\hline 8 & $120 / 2$ & $65,7 / 1,09$ & Continued \\
\hline 14 & $168 / 2,8$ & $119 / 1,9$ & Coiffures on mannequin heads \\
\hline 15 & $156 / 2,6$ & $114 / 1,9$ & Continued \\
\hline 21 & $195 / 3,2$ & $103 / 1,7$ & Continued \\
\hline 22 & $145 / 2,4$ & $88 / 1,4$ & Continued \\
\hline \multirow[t]{2}{*}{ October 19} & $166 / 2,7$ & $0 / 0$ & Completive trial of techniques \\
\hline & Totals $=19,6 \mathrm{~h}$ & $=9,8 \mathrm{~h}$ & \\
\hline
\end{tabular}

The data consists of approximately $30 \mathrm{~h}$ of video recordings with 16 students and four teachers. ${ }^{2}$ The recordings from which the example for this article is selected are made during a series of seven lessons at first-year level on the subject of handicraft, ${ }^{3}$ introducing the students to various hairdressing techniques (see Table 1 above).

The analytical work started with repeated viewings of the entire material, taking notes and marking episodes to return to such as teacher-student interactions concerning problems, solutions, assessments, possibilities of choice and different techniques. The selected episode is an approximately $3 \mathrm{~min}$ long case of dyadic teacher-student interaction. Guiding the selection of the episode is on the one hand a temporal delimitation that permits following a feedback interaction between teacher and student from the start to the end. A second criterion is that the interaction should consist of feedback regarding an ongoing task within creative subject content.

The analytic CA approach taken in this article is to develop a comprehensive account of a single instance of embodied talk in interaction, following the sequential unfolding in which each turn is responding to a preceding one, so as to build an action (Schegloff 2007). It is therefore possible for the analyst to follow what the participants are orienting to, through what is made relevant by their actions and embodied resources. The analytic method involves moving back and forth between a detailed examination and a synoptic view, combining the video viewing with the transcribing process. The excerpt is a two-line transcript, with the participants' first language, Swedish, followed by the translation into English. In the transcripts, the notation system developed by Jefferson (2004) is used, combined with frames of anonymized still images from the recordings, to visualize analytically important aspects of the interaction which the logocentric transcripts cannot transmit (cf. Mondada 2007). In line with the theoretical and methodological framework of the study, the selected empirical material has been analyzed in various data sessions together with researchers from the field, as well as presented and discussed in seminars with senior researchers throughout the analytical process.

\footnotetext{
${ }^{2}$ The participants have given their written consent to be recorded and represented anonymously in research presentations and publications.

${ }^{3}$ Further information about the handicraft subjects from the National Agency for Education: http://www. skolverket.se/polopoly_fs/1.194820!/Handicraft\%20studies.pdf
} 


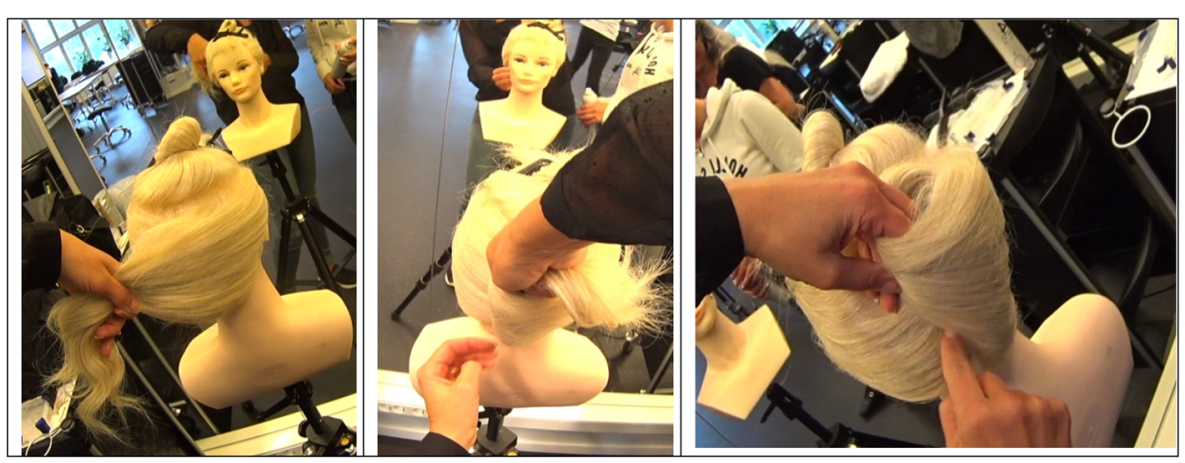

Fig. 2 Still images from the teacher's demonstration of the making of the French Twist

\section{Analysis and Findings}

During the lessons, the teachers circulate in the classroom, mostly interacting with the students on a one-to-one basis. There are also multi-party as well as peer interactions. At times a group of students gather around one particular work to receive the teacher's instructions. They have had demonstrations of backcombing and attachment techniques as well as the making of some different coiffures such as the 'French Twist' and the 'Rose', and worked individually on techniques of back- and smooth combing and braiding. The assignment in this particular lesson is to reproduce an individual coiffure of a French Twist on a mannequin head. The students are instructed to choose between a big or a small size of the twist in making the shape, as well as assuring its placement either centered or to the side, not showing any pins. At their disposal they have a filmed step-by-step demonstration of the French Twist from YouTube. ${ }^{4}$ There are basic techniques to follow in order to get the hair in position at the back and on the top. Beyond these basics there are possibilities for the students to experiment and find solutions on their individual mannequin head, when it comes to the hair left over such as on the top and the sides. The students also get individual demonstrations from the teachers when needed, as shown in Fig. 2 above:

The episode is analyzed as a feedback trajectory in six separate excerpts. By highlighting the resources that are made most salient by the participants, each excerpt shows a particular aspect of the studied feedback practices within creative subject content. As will be shown, the episode can be followed sequentially as distinct phases in problem solving: a) detection, b) investigation, c) calibration, d) exploration, e) demonstration, f) solution.

The episode starts with the teacher and the student ${ }^{5}$ evaluating the work in progress. The student is approaching the end of her coiffure, in which the shape of the hairstyle is their main focus of attention (Table 2).

\footnotetext{
${ }^{4} \mathrm{https}: / /$ www.youtube.com/watch?v=owiW-2PxQHw

${ }^{5}$ In the excerpt the " $\mathrm{T}$ " represents the teacher and "S" the student. For a complete transcription key, see Appendix Table 8.
} 
Table 2 Excerpt 1 Initial assessments

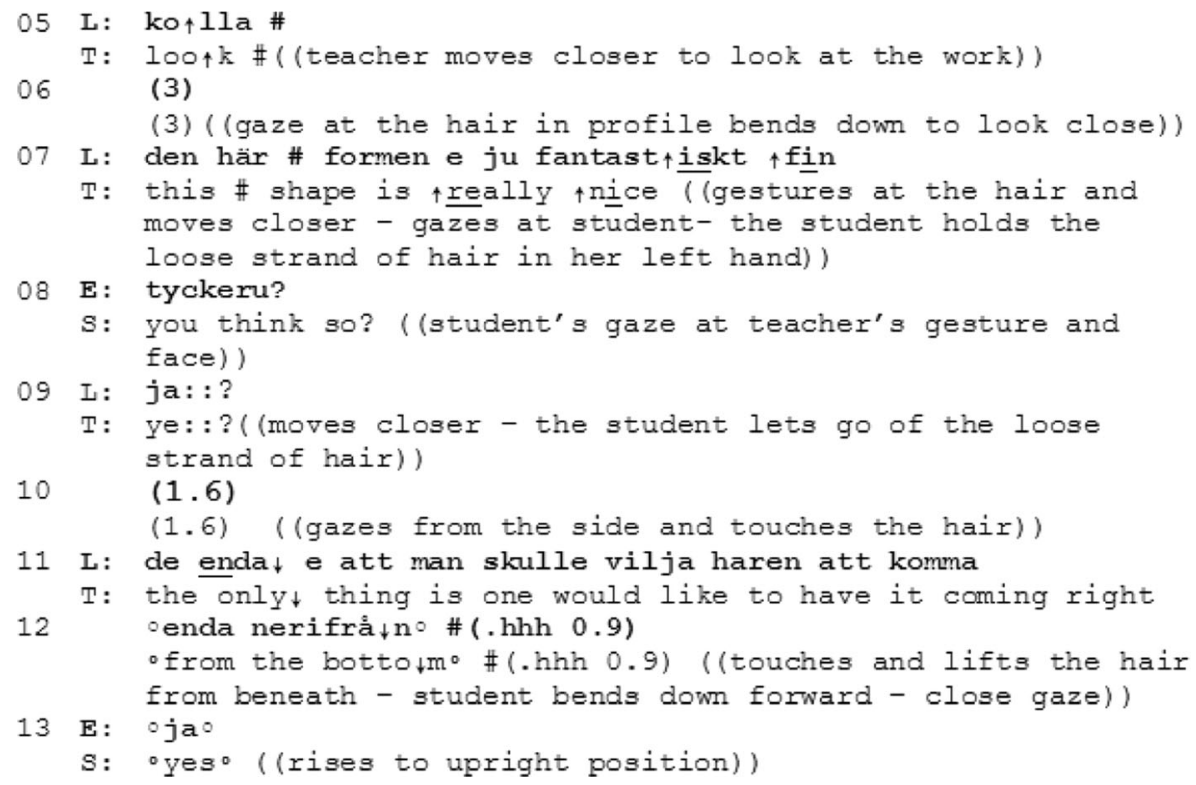

When the excerpt begins, the teacher has just finished talking with another student and in approaching this one, seeing her work she exclaims "loo $\uparrow \mathrm{k}$ " (line 5), moves to look at the hair in profile and bends down to get a closer view of the twist (line 6). Having thus caught an overall view of the student's work, she initiates feedback with an assessment, launched as praise in line 07. The teacher's rising pitch on "loo $\uparrow \mathrm{k}$ " and " $\uparrow$ really $\uparrow$ nice" highlights the assessable together with a coupled gesture on the hair followed by her gaze at the student showing that she is supporting what the student has made of the hair. The student gazing back with a confirmation seeking question "you think so" in line 08 , is endorsed with the teacher's "ye::s?" in line 09 as she moves closer looking at the hair. In their mutual orientation to each other their focus is jointly on the work in progress. This is followed by a short silence in line 10 in which they both look at the hair. The teacher touches the twist by pushing some hair slightly inwards, followed by another assessment in which she lowers her voice with falling intonation in lines 11-12 on "only $\downarrow$ " and "from the botto $\downarrow \mathrm{m}^{\circ}$ ", showing that she is not entirely satisfied with how the student has made the twist from beneath. The student responds with moving forward to get a closer look and answers with an acknowledgement token "yes" (line 13), produced with a lowered volume as well, aligning to the assessment made by the teacher, receiving the critique as factual information (Fig. 3). 


\begin{tabular}{|c|c|c|}
\hline & 7 & 1 \\
\hline $\begin{array}{l}05 \text { L: ko lla } \neq \\
\text { T:loo } k \neq \\
\text { ((the student is working } \\
\text { on a loose strand of } \\
\text { hair on the side and the } \\
\text { teacher moves closer to } \\
\text { look at the work)) } \\
\text { 06 (3) ((the teacher } \\
\text { looks at the hair in } \\
\text { profile - bends down to } \\
\text { look close)) }\end{array}$ & $\begin{array}{l}\text { 07 L: den här } \neq \text { formen } \\
\text { e ju fantast } \uparrow \text { iskt } \uparrow \text { fin } \\
\text { T:this f shape is } \\
\uparrow \text { really } \uparrow \text { nice } \\
\text { ( (gestures at the hair } \\
\text { and moves closer - } \\
\text { gazes at student - the } \\
\text { student holds the } \\
\text { loose strand of hair } \\
\text { in her left hand and } \\
\text { gazes at teacher's } \\
\text { gesture)) }\end{array}$ & $\begin{array}{l}\text { 11 L:de enda } \downarrow \text { e att man } \\
\text { skulle vilja haren att } \\
\text { komma } \\
\text { T:the only } \downarrow \\
\text { one would like to have it } \\
\text { coming right } \\
\mathbf{1 2} \text { oenda } \downarrow \text { nerifrå } \downarrow \text { no\# (.hhh } \\
\mathbf{0 . 9 )} \\
\text { ofrom the botto } \downarrow \\
0.9) \text { ( (touches and lifts } \\
\text { the hair from beneath)) }\end{array}$ \\
\hline
\end{tabular}

Fig. 3 First assessment with praise and critique (lines 8-10 omitted)

In this first excerpt, the participants' use of gestures and talk organize feedback through salient resources such as gaze and prosody. The analysis shows how the interaction starts with an assessment of the ongoing work synchronized with gestures on the material. Environmentally coupled gestures are a way to organize visual events and create salient loci of joint attention and co-participation (Goodwin 2013). Such manifest actions display certain, albeit tacit standards, in which the assessable (the shape of the twist) is gradually made visible. Thus, indexing the assessable, the teacher makes publicly visible to the student as well as to others seeing the episode, that the vertical shape of the twist is being assessed as nice but not its bottom section. Visual events such as gaze are salient as a resource in assessing the ongoing work as well as in the professional skill to be learnt and calibrated. "All vision is perspectival and lodged within endogenous communities of practice" (Goodwin 1994, p. 606). Participating in 'profession-like' activities entails being instructed in how and what to see; vision is thus selective (Goodwin 2001). In this, prosodic features such as rising and falling pitch laminate meaning. Accordingly, the feedback is organized through prosody together with gaze and in this phase of detecting the problem.

In the following excerpt the teacher and the student continue their evaluation of the work at hand (Table 3): 
Table 3 Excerpt 2 Problem investigation

14 L: nu vill jag nästan inte pilla pá den för jag tyaker T: now I almost don't want to fiddle with it because I think ((bends down - touches the twist - student joins in touch))

15 att du fått en så fin- förstår du att det blir som ett- \# that you've got it so nice-you understand it's like a- \# ((gazes and \# sticks her finger into the hair from below))

17 E: ja preci: :s

S: yes exa: ctly ((gazes and lifts a loose strand of hair from the side))

18 L: att de blir som ett ihấ:l där.

T: that it is like a tho:le there. ((rises and sticks her fingers into the hair))

19 E: ja:

S: Ye:s( (bends forward, gazes, sticks her finger into the hair))

20 L: hur kan man(.) kan man- va har du tänkt att göra mere där?

T: how can one(.) can one- what are you going to do with that ( (moves closer and points to the loose strand of hair on the side))

21 E: ja hade tänkt ( ) sätta en fläta \# så: ungefär(.) typ där S: I was thinking ( ) put a plait something \# like thi:s(.) there ( (student takes the strand and puts it along the side of the twist))

22 L: $m m ?$

T: mm? ((joint angle of gaze from behind))

23 E: där men

S: there but ((holds the strand in her hand))

$24 \mathrm{~T}: \mathrm{mm}$ ?

L: mm? ((moves to gaze in profile))

25 E: ( ) sã: osåo

S: () like tha:t olike thato

26 (4.8)((the teacher gazes from the side - lifts the hair and tightens it - the student's gaze follows her moves))

27 E: man kanske kan strama till li:te

S: maybe one can tighten it a bi:t ((the teacher shoves hair into the twist - the student pulls some hair upwards))

(1.3) ((joint gaze and touch at the hair - the teacher tightens the twist - the student bends for a closer look))

In continuing the feedback regarding the hairstyle, the participants indicate salient parts of the hair through touch (line 14). The materiality of the twist is collaboratively investigated step by step under the guidance of the teacher, first having the problem oriented to as the "个ho: le" (line 18) displayed by the teacher's gesture in line 16, when she sticks her finger into the hollow part of the hair, providing the student with experiential access through demonstrating embodied procedures of touch (cf. Zemel and Koschmann 2014). The student aligns in her response in line 19 with an acknowledgement token and laminates the teacher's gesture by sticking her own finger into the hollow part of the hair. 
When the teacher asks the student about a solution (line 20), she shifts from using the generalizing pronoun "man" ("one") to the personal and specifying "du" ("you") addressing the student herself, thus leaving the floor to the student, who responds by showing how she is planning to make a plait of the loose strand of hair beside the hollow part (line 21). The student's talk is quiet and sometimes hard to distinguish, but the coordination of bodily stance and gestures creates a visual display of what she orients to, not the twist itself but how to arrange the plait beside it. Getting access to the material under investigation to show a candidate solution, thus allows the student to make her knowing public to the teacher. The teacher simply responds with the vocal continuer "mm?" (line 22), a slight questioning contour with its rising intonation. Vocal continuers merely treat the telling as still in progress (Lindström and Sorjonen 2012), showing that the candidate solution the student has presented in line 21 , is not really supported or given much attention. The responses from the teacher indicate that there is a tacit solution to the problem at hand, to which she is orienting. Not picking up the suggestions from the student (lines 21, 23 and 27), her responsive actions in lines 22, 24 and 26 moving from joint gaze to the side, nevertheless make her own understanding of the assessable public as something different from the student's (Fig. 4).

The analysis of this excerpt shows how tactile resources are used and made relevant by the participants as the teacher expands on the previously assessed defect by using touch as a salient resource of feedback. There seems to be an implicit right answer to a format of so-called 'known-answer question' closely identified with the setting and activity in which they figure (Schegloff 2007), common in institutional settings and classroom interaction. Touch is thus, as a resource, a "diagnostic criterion" (Goodwin 1997, p. 127) in the feedback

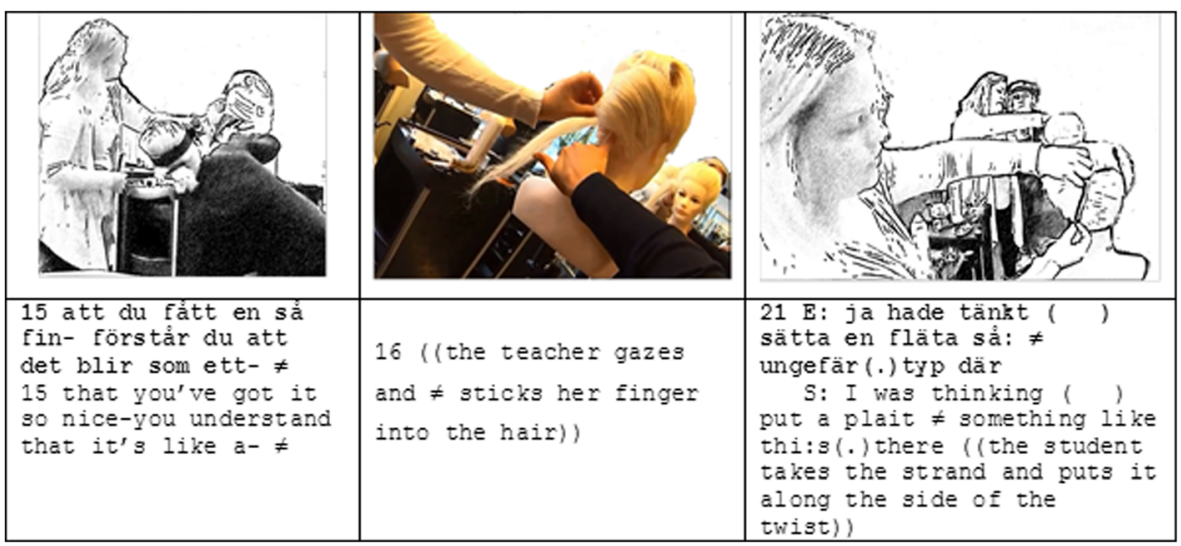

Fig. 4 Problem investigation with candidate solution (lines 17-20 omitted) 
practice to investigate and laminate experience tactilely of how the worked with material feels; the empty space inside the twist, by which the student coparticipates in and gets access to tacit dimensions of the professional knowing, being used in the process of evaluation. The feedback is accordingly organized through the use of touch as a salient resource in this phase of investigating the material.

In the following excerpt the participants continue their evaluation of the coiffure (Table 4):

In this excerpt, the teacher instructs about the importance of the angle vision and body position as she directs the student to move her body to the side to get the right perspective of the hairstyle in profile (line 29). As a consequence, they exchange body positions so the student can look at the twist in profile, changing the participation framework with it when the student gets access to a new angle of vision (see Fig. 5). The teacher asks the student if she now sees the shape (lines

Table 4 Excerpt 3 Body position as angle of vision

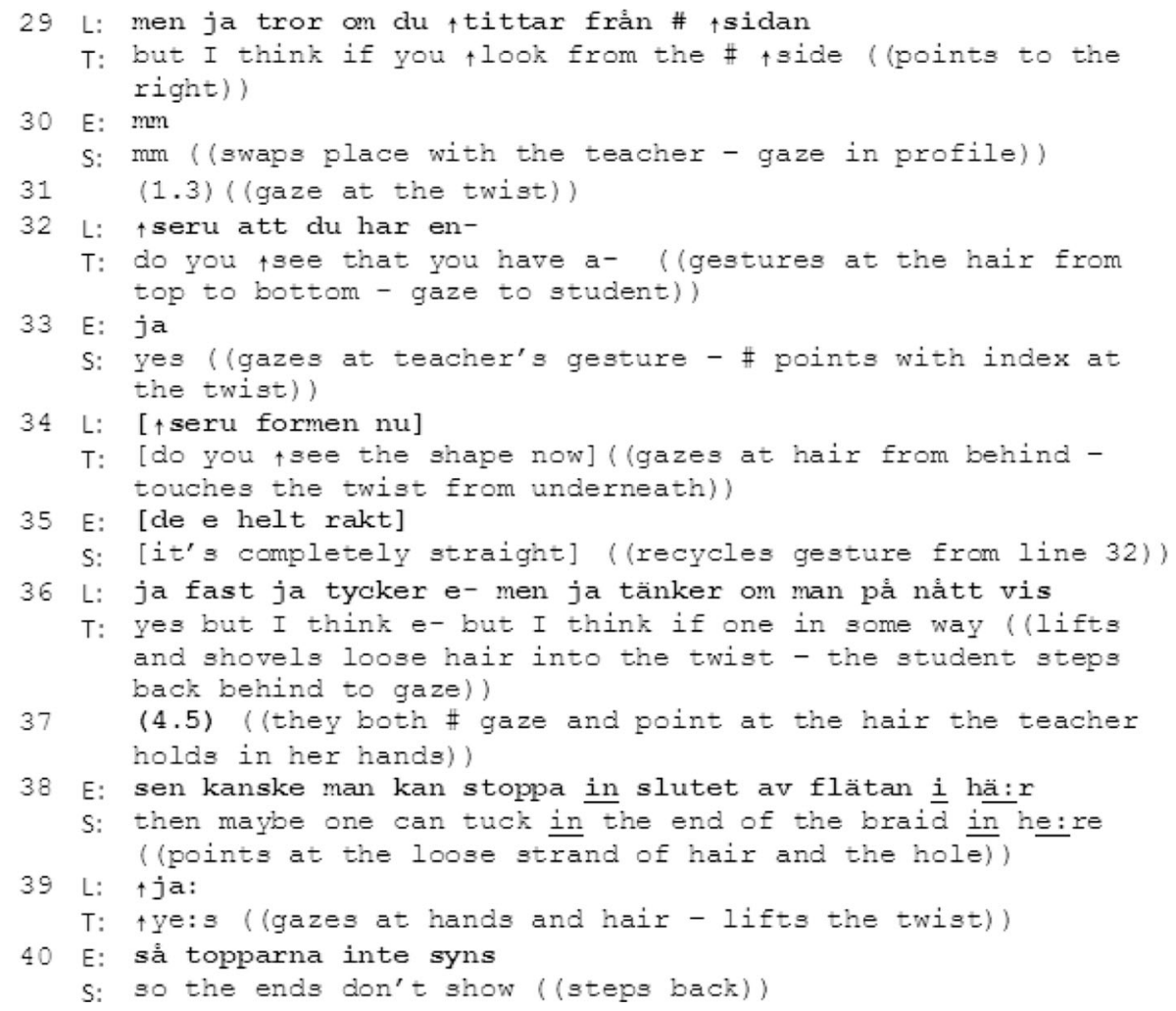




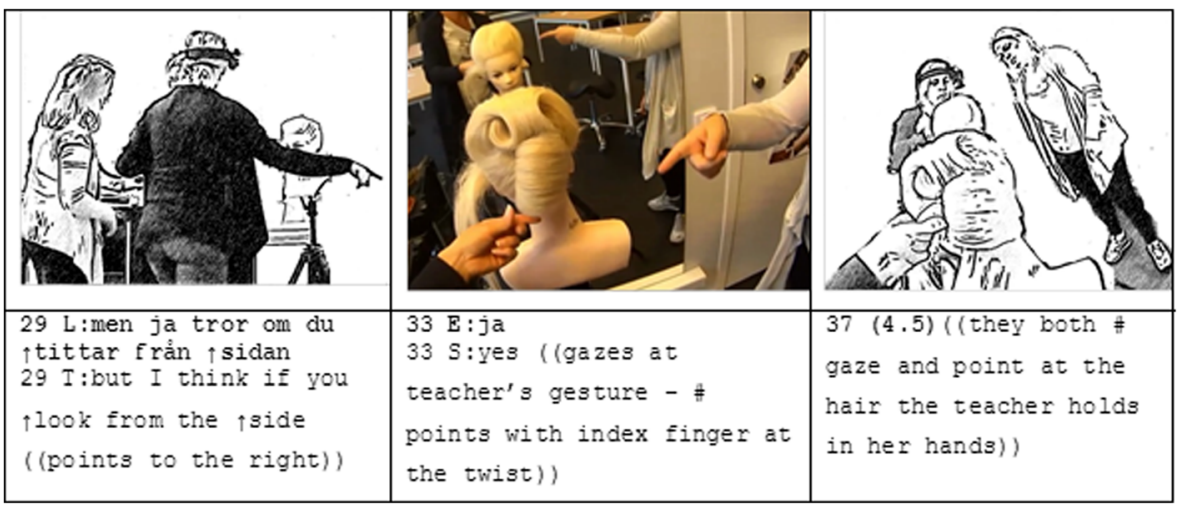

Fig. 5 Participatory embodied assessment (lines 30-32, 24-36, 38-40 omitted)

32 and 34), repeating "do you $\uparrow$ see". The restart in line 34 occurs when she brings her gaze to the student, in request for her gaze (Goodwin 2001). In doing this she prompts the student to adopt an analytic vision, laminating her question with cues such as cut off, gaze and coupled gesture (line 32), expanded in line 34 in overlap with the student's assessment "it's completely straight" (line 35). The teacher responds by gazing at and lifting the hair (line 36), followed by a silence in which they both look at the twist (line 37). The suggestion of the student in line 38 is again not taken up by the teacher, who merely responds with an acknowledgement token, not giving the candidate solution proposed by the student any further attention, just confirming with rising intonation "^ye:s" (line 39). The teacher still orients tacitly to the shape of the twist whereas the student is orienting to the hair on its side.

The analysis of excerpt 3 shows how body position with particular focus on angle of vision is made especially relevant as a resource of feedback. The exchanging of body positions shows how professional vision is performed with the body through selective postural orientation to build participation in situated activities which can be understood as "...socially organized ways of seeing and understanding events that are answerable to the distinctive interests of a particular social group" (Goodwin 1994, p. 606). Drawing on the same study by Goodwin, Gåfvels (2016) also shows how the forming of skilled vision involves sharing the visual perspective spatially as well as disciplinarily. Learning 'right ways of looking' entails co-participation in selective and relevant activities. The way in which the student moves her body is thus seen as responsive actions of lamination (Goffman 1981; Goodwin 2013), and not simply reproducing the teacher's. In pursuing a common activity such as evaluating a piece of work in progress, the participants need to understand each other to build actions co-operatively. Situated in an educational practice such as this, a co-operative calibration of professional vision is organized through actions in which a skilled participant guides less skilled participants (Goodwin 1994, 2013). The analysis of this excerpt shows how the body position is a salient resource in feedback to calibrate the angle of vision to build a common gaze at the assessable.

In lines 41-55 (omitted from transcript) the teacher and the student continue to investigate and manipulate the hair. The teacher reminds the student of the importance of looking in profile and leaves the floor to the student, who sets out by taking a pin from her toolbox, fiddling with the hair she is about to tighten with the tool. In the following excerpt, the student and teacher continue laminating gaze (Table 5): 
Table 5 Excerpt 4 Pronominal shifts

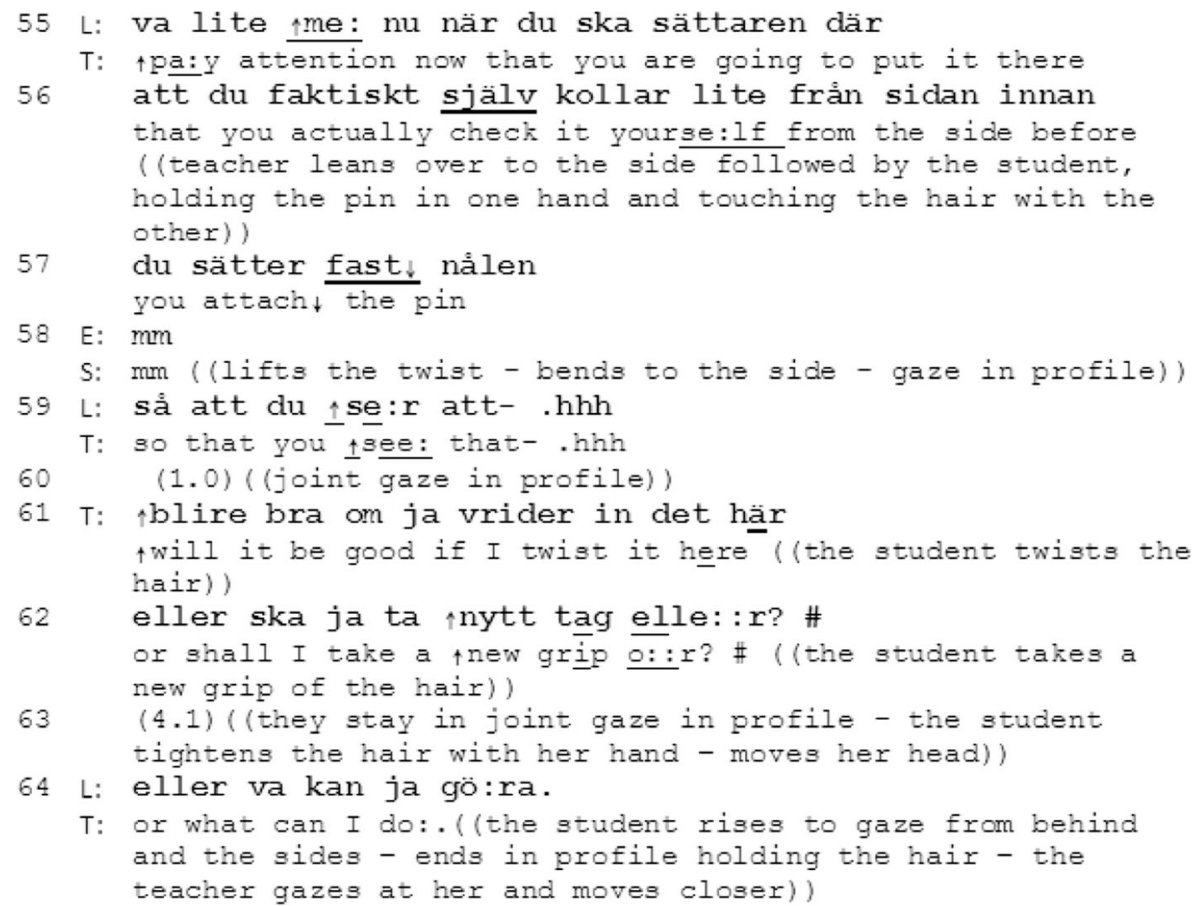

Having observed the student's bodily posture and hesitant movements to attach the pin, the teacher now addresses the student with the personal pronouns "du" ("you") and "själv" ("self") in lines 55 to 57 , prompting her to use gaze. The student not only aligns with the teacher in her talk (line 58); her participation is also displayed in her coordination of bodily stance as she follows the teacher's instructions in moving her body and gaze in synchrony with the teacher's talk. After a short silence in line 60 when they both look at the coiffure, the teacher changes her use of pronouns from directing with "du" ("you") to using the pronoun "jag" ("I"). This is not to be regarded as "selftalk', rather it is to be seen as 'reasoning aloud' as an instruction to the student, modelling with her talk, body position and gaze how problem solving as exploration can be done: " $\uparrow$ will it be good if I twist it here or shall I take a 个new grip o::r?" (lines 61-62). The student is responding to this with actions displaying embodied alignment of performing the teacher's talk (lines 61-62). The teacher's use of the first person pronoun can thus be seen as a projected self of the student, coordinated with her bodily displays (Goffman 1981). This shift in talk changes the participation framework when the teacher talks as from the point of view of the student, prompting the student to join the type of experience she is modelling in her talk (Goodwin 2000). Sharing the same position of body allows them to synchronize their angle of vision, as shown in the second still image in Fig. 6 below. In line 63 there is a longer silence in 


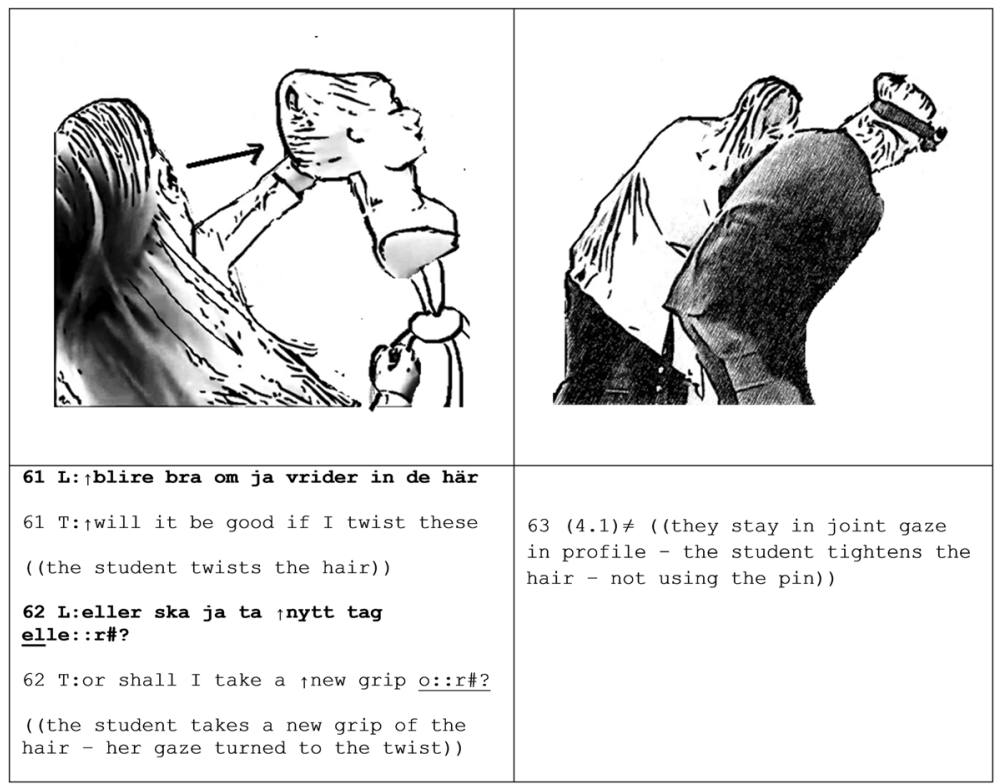

Fig. 6 Still images of gaze and body positions from head-mounted and handheld cameras

which they both gaze at the hair in profile while the student tightens the twist with her fingers. In response to the teacher's question "or what can I do:" (line 64), leaving her the floor, the student moves her body and gaze from one side to the other, joined by the teacher.

The analysis shows how lexical features, such as shifts in the use of pronouns, are made salient as resources in the feedback. Shifting between pronouns entails changes as a form of social management of "co-bodily presence" (Goffman 1982, p. 4). Accordingly, speaker and listener co-construct the unfolding activity in progress (Goodwin 2006). The feedback is thus organized through shifts in pronouns in this phase of exploring the problem at hand.

In the following excerpt, the teacher and the student continue manipulating the twist (Table 6).

Responding to the student's embodied display of being hesitant of how to proceed with tightening the twist (line 65), the teacher moves closer and takes a pin which she attaches into the hair by twining it (line 66), creating a sense of community by the use of the impersonal pronoun "man" ("one"). In this she lowers the volume of her voice as if whispering, telling what she is doing embedded in laugh particles and gaze (lines 6672). With affiliative displays such as turning her face to gaze at the student smiling (lines 66-68), she invites the student to move closer and co-participate, mitigating the affront of a corrective action. In response, the student leans over to gaze (line 68). The teacher also extenuates the difficulty, saying "if one is $\uparrow$ lu: cky" (line 70), turning to the student who joins her gaze and smiles. In continuing with "just by twisting some 个turns" (line 72), the teacher simultaneously demonstrates how to lift the twisted hair using a pin. The laughter embedded in her utterance is responded to by the student (line 72), overlapping with a response cry: "ye::s sma::rt. heh" (line 73), participating by 
Table 6 Excerpt 5 Prosodic features

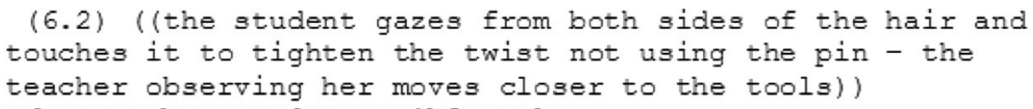

66 L: ade man kan gö-kan-o ibl $\downarrow$ and

$T$ : 'what one can d- can-o $\downarrow$ sometimes (bends down, takes a pin and sticks it into the side of the twist, turning it around to tighten the hair - the student gazes at her hand and the hair))

68 L: okan det funka att mano liksom tạr en nå:l (1.2) å sẹn

$\mathrm{T}$ : Dit can work if one takes a pi:n (1.2) and then ((the student leans over to get a closer gaze - the teacher turns her head to her and smiles))

70 L: om man har 1 tu: $r$

$T:$ if one is 1 lu: cky ((turns her gaze to the hair))

71 E: ja:

S: ye:s ((smiles-gazes at the hair and the teacher's gestures))

72 L: såblire brä ge-[bara genom att man heh

T: it'll be good by-[just by heh ((gaze at the student's smiley face, laughs and twists the pin))

73 E:

[ja: : sma: :rt heh

S: [ye: :s sma: :rt heh ((smiles and laughs -

74 L: leans forward and to the side to look in profile))

$\mathrm{T}$ : att man snüra nâra pvarv

twisting söme †turns

endorsing the preceding affective stance displayed in the teacher's actions. The participants thus attend to each other with laughter and smiling faces, coordinated with and sustaining the ongoing actions (Jefferson 1984), as represented in the second frame in Fig. 7 below.

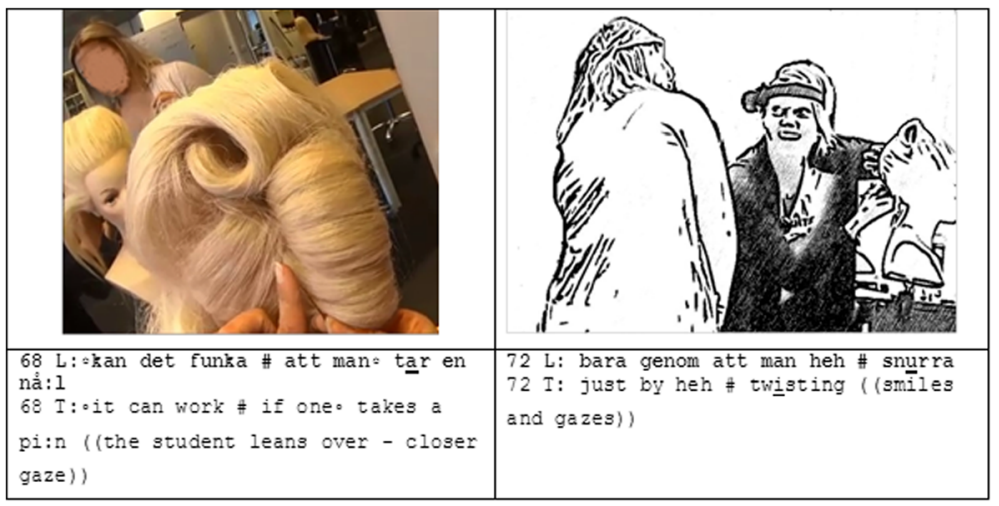

Fig. 7 Demonstrating tool use (lines 69-71 omitted) 
The analysis of the excerpt shows how the use of prosodic features such as volume and laugh particles are made relevant as salient resources in the interaction, creating affiliative displays (cf. Lindström and Sorjonen 2012). The teacher provides the student with a visible event of a professional hairdresser in action, laminating tool use with the same kind of pin that the student holds in her hand, unused. Performing demonstrations complements spoken language using the material environment to organize actions in ways that talk cannot, and requires simultaneous attention (Goodwin 1994), here in the interface between seeing, talk, touch and tool use. In this, feedback is organized through resources of decreased volume, laughter and smiles creating a local environment of ease and solution where the affiliative displays are mutually produced. Accordingly, the teacher and student co-construct a participation framework, strengthening the social relations of the local educational interaction, simultaneously with the teacher demonstrating professional tool use.

In the following and last excerpt, the teacher and the student approach the end of their common activity of handling the twist (Table 7):

Table 7 Excerpt 6 Joint embodied focus

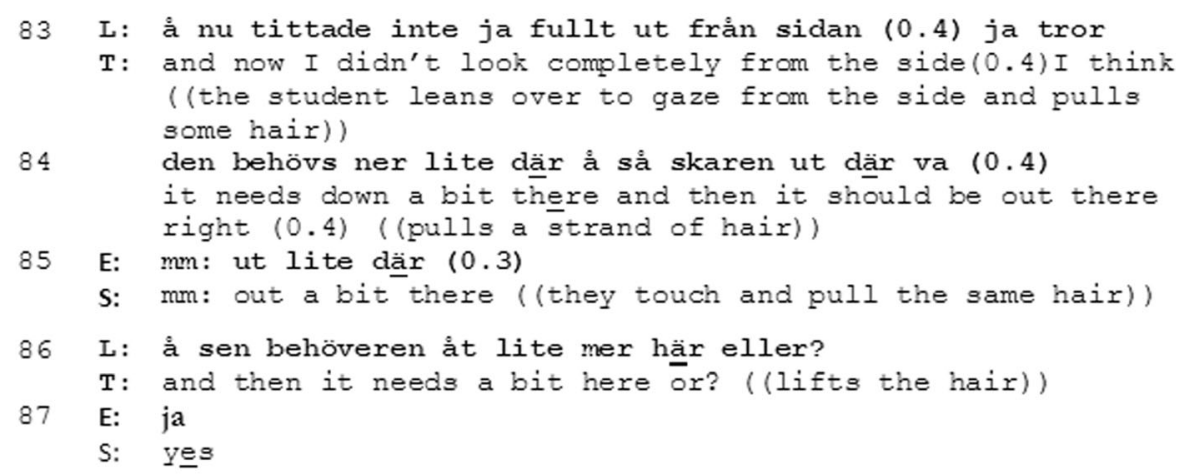

(In lines 88-101 the teacher and student continue their co-manipulation of the hair and the student tells her and shows with a coupled gesture in the hair how she plans to tighten the hair in order to get the shape less straight - acknowledged by the teacher as a way to proceed and 'twist it around')

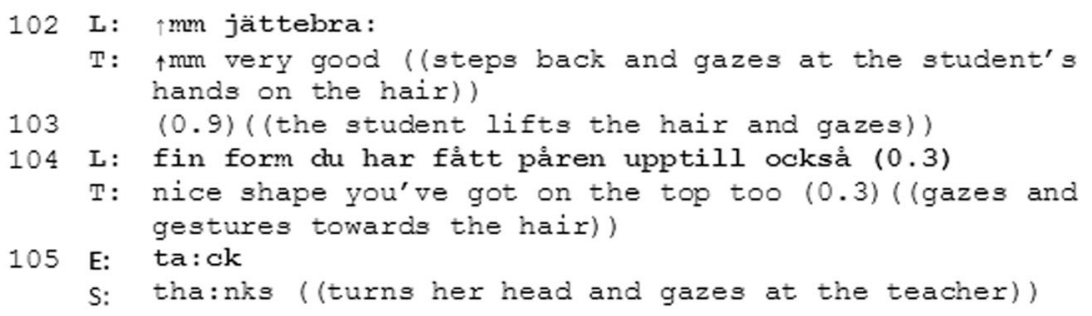


In this excerpt the participants continue manipulating the hair; the teacher not looking in profile gives the student access to be the one gazing from the right angle (line 83). The teacher pulls the hair where the twist needs to be corrected, showing the student the precise placement with her gesture (lines 84 and 86), asking for confirmation from the student, who responds and coparticipates with laminating gestures (line 85). As the student both tells and shows (lines 88-101, omitted from transcript) how she plans to proceed, the teacher responds by upgrading with " $\uparrow \mathrm{mm}$ very good" (line 102) followed by the student's gaze and gesture on the hair (line 103). Now that they have reached a joint focus on the assessable as the straight line of the twist, the teacher orients to the upper part of the coiffure, assessing it as "nice shape" (line 104). This shows how visible phenomena are oriented to selectively (Goodwin 2001), as previously displayed in how the student and teacher oriented to different parts of the hair. With the student's "tha:nks" (105) turning her gaze to the teacher in a terminal contour, the interaction closes (Fig. 8).

The analysis of this last excerpt shows how the feedback is done with resources made salient such as deixis, synchronizing talk with gesture. Deictic gestures have indexical components that highlight specific spots and produce multiple meaning, since touch, gaze and talk mutually elaborate each other relevant to the work at hand (Goodwin 2003). By prompting the student to participate by asking for her confirmation, the teacher gets a position to analyze and evaluate her actions of adequately locating and characterizing relevant phenomena in the work in progress, showing how gaze is used professionally as to what is relevant gaze (Goodwin 2001). With their gestures the participants establish and position the assessable referent in the scrutinized material by simultaneous deictic terms such as "there" and "here" (lines 84 and 86). This

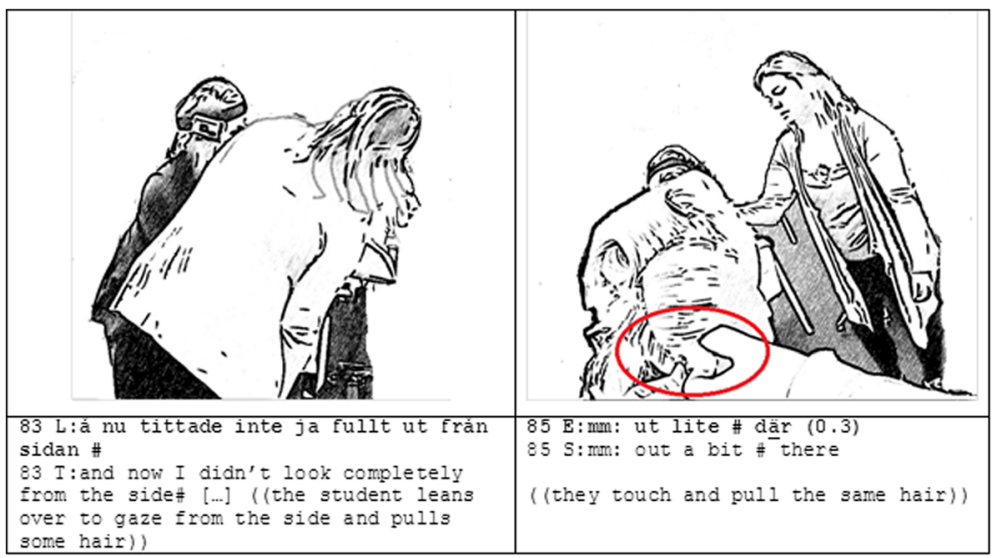

Fig. 8 Collaborative solution (line 84 omitted) 
way of highlighting with precision would not be possible without the simultaneous use of multiple resources, such as gaze, talk and touch. As the teacher orients to the student as a participant with the ability to see in the complex perceptual field they are attending to, as well as to handle the material, she upgrades her as someone accountable who is capable of evaluating her own actions and answering questions. Having thus co-participated in the exploration of the problem, they now accomplish a participation framework in which they have reached a solution in joint and embodied focus of the assessable. As the feedback through deictic resources is directly tied to the material worked on as visible events, the participants are able to display tacit understanding through talk and gestures, thus solving the problem.

In sum, the analyses of the six excerpts show how the feedback practices within creative subject content are organized as a feedback trajectory through sequences of six distinctive phases in which certain resources are made salient. The resources that have received particular attention include: a) gaze and pitch in detection, b) touch in investigation, c) body position in calibration, d) pronouns in exploration, e) volume and laugh particles in demonstration and f) deixis in solution. The resources serve different functions in organizing the feedback practices within creative subject content, while mutually elaborating each other in laminating meaning. To reach a mutual understanding of what the assessable referent is, feedback is built moment by moment through this multi-dimensional use of resources in collaboratively locating features that constitute shape in the profession of hairdressing. Feedback is thus done in a process of embodied and material co-ordination.

\section{Discussion}

The aim of this study was to explore feedback practices in teacher-student interaction within creative subject content in hairdressing education. The results show how feedback is a sequentially unfolding practice constructed turn by turn by the participants' responsive actions in the material environment, providing publicly available displays of the interaction. The analyses have found the studied feedback to be organized as a trajectory, starting with problem detection and ending with the solution, constructed from moment to moment by way of the participants' selective use of resources in their orientation to each other and of the work under evaluation. In this the participants continually attend to each other to accomplish a mutual understanding.

The materiality of the work provides an intimate coordination, as shown by the participants' collaborative actions such as assessments and gestures. The results show how feedback requires situated use of the body and the material environment as a way of visibly displaying one's orientation and understanding. These aspects are largely overlooked in much of the transmissive understanding of feedback, criticized as mere "telling" (Sadler 2010, 2013) or "product" (Price et al. 2013), in which the teacher is seen as giving the student verbal information. This study provides evidence of how 
feedback practices are produced in multimodal interaction, showing how the student and teacher continually attend to each other and display their understanding of the assessable in the feedback with their bodies and tools, as well as the material object under production. As has been pointed out by other researchers within the same educational field (Ekström 2012; Gåfvels 2016), handicraft is a highly embodied discipline in which interacting with objects and material is just as important as interacting with others.

Furthermore the results of this study show that the tacit dimensions of the professional knowledge are gradually displayed through embodied actions of lamination, performed by the teacher as well as the student in their feedback practices. 'Shape', as the assessable referent, is explored turn by turn in the contingency of the interaction between the participants as well as with the material. The student is provided with resources she can operate on and co-participate with, such as the skilled directives of the teacher to organize her body position to get the relevant angle of vision, thus making public the actions that define the work of the community (Goodwin 2013). Distinctive ways of knowing are created and lodged there: "Members of such communities thus face, as part of the intrinsic organization of action itself, the task of building new members who can be trusted to see, understand and act upon the world in relevant ways" (Goodwin 2013, p. 9), as shown throughout the interaction in the teacher's professional guiding of the student, making tacit knowledge public.

There is an understanding that in the vocational classroom the questions asked are not those with 'known answers', as the context entails a more heuristic type directed to explore the material production of some kind (Filliettaz 2011; Schön 1983). However, this study shows that there is a form of 'right answer', gradually displayed. The analyses have shown that there are qualities for the overall shape of the coiffure, as well as the techniques of getting this shape right, as matters of reproduction and mastery of technique. These largely tacit qualities are oriented to by the teacher from the start, but instead of 'giving the right answer' she lets the student get access to co-participate in exploring these qualities step by step.

A problem-solving activity involves an ability to handle resistance from the material as well as understanding the creative subject matter (Tanggaard 2014a). What this study shows, in addition, is the finely tuned coordination of resources used by the participants in this kind of interaction, creating an environment of professionalism as well as affiliation. The subject content of creativity is emerging as intertwined with technical handicraft skills through embodied actions of seeing and handling the material. It is through participatory enactment on the material that the creative subject content is made visible as 'doings', embedded in the task of reproducing a French Twist, finding solutions such as 'what to do with the strand of hair on the side' or solving problems such as 'how to tighten the twist to get the right shape', in line with the understanding of creativity as consisting of actions of both reproduction and exploration (Tanggaard 2014b). As shown in other studies, the creative subject content is part of the technical process of the craft to be learnt; in mastery as an aesthetic component (Tyson 2014), directly related to materiality (Gåfvels 2016) or simply organized in less articulated displays (Asplund and Kilbrink 2016). It is thus through materiality explored in interaction between participants that various aspects of aesthetics and creativity are 
made public, emerging embedded within layers of instructions (Ekström 2013; Ekström and Lindwall 2014) or as disciplinary knowledge displayed through assessments (Lymer 2013).

What this study shows is how feedback is a fundamentally problem-solving cooperative practice at the very center of the professional knowing to be learnt, however a multifaceted process as displayed in the feedback trajectory starting from problem finding, proceeding through phases of problem setting to a final solution. It shows the need to take a participant's perspective on feedback practices in order to understand the complexity they display. Feedback has typically been analyzed with a logocentric approach, understanding the spoken or written as self- contained domains. The $3 \mathrm{~min}$ of analyzed video data in this article reveal a rich and multilayered feedback done by the participants in exploring and identifying the assessable. Feedback itself turns out to be embodied when taking into account the diverse sets of resources and meaningmaking practices that participants collaboratively display through ongoing processes of action (Goodwin 2001). The contribution of this article is thus to empirically substantiate how feedback is organized in collaborative and materialized practices. The analyses of the resources that the participants themselves make salient in subsequent phases of problem solving, display tacit dimensions of the assessable creative subject content.

\section{Appendix}

Table 8 Transcript Conventions

(.) A dot in parentheses indicates a brief interval.

\begin{tabular}{ll}
\hline & A dot indicates final falling intonation. \\
hhh & Dot and three letters indicate inbreath. \\
heh & Indicates laughter. \\
$(3.4)$ & Number within brackets indicate end of word and beginning of next. \\
() & Empty parentheses indicate inaudible speech. \\
No & Underlining indicates some form of stress or emphasis. \\
$:$ & Colons indicate prolonging of the previous sound. \\
[ & Words enclosed with degree signs indicate that the talk between them was markedly quiet. \\
$i$ & Square brackets indicate overlapping talk. \\
$?$ & An inverted question mark indicates a slightly rising intonation. \\
$\uparrow$ & Arrow up indicates marked shift in pitch up. \\
$\downarrow$ & Arrow down indicates marked shift in pitch down. \\
$=$ & Equal signs indicate no break or gap between the lines. \\
$(($ & Double parentheses contain analyst comments or descriptions. \\
$\#$ & Marking the exact position of a particular frame of the video in transcripts as well as figures. \\
An indicative translation is provided line per line, in order to help reading the original. It is presented in black \\
to discern it from the original language in bold. \\
\hline
\end{tabular}


Open Access This article is distributed under the terms of the Creative Commons Attribution 4.0 International License (http://creativecommons.org/licenses/by/4.0/), which permits unrestricted use, distribution, and reproduction in any medium, provided you give appropriate credit to the original author(s) and the source, provide a link to the Creative Commons license, and indicate if changes were made.

\section{References}

Amabile, T. M. (1996). Creativity in context. Boulder: Westview.

Andersson Gustafsson, G. (2002). Den inre teatern i lärandet: En studie om kunskapsväxandet inom hantverk. Thesis, Stockholm: KTH.

Asplund, S. B., \& Kilbrink, N. (2016). Learning how (and how not) to weld: Vocational learning in technical vocational education. Scandinavian Journal of Educational Research, 1-16. doi: https://doi.org/10.1080 /00313831.2016.1188147.

Berner, B. (2010). Crossing boundaries and maintaining differences between school and industry: Forms of boundary-work in Swedish vocational education. Journal of Education and Work, 23, 27-42.

Billett, S. (1995). Structuring knowledge through authentic activities. Unpublished $\mathrm{PhD}$ thesis. Brisbane: Griffith University, Faculty of Education.

Billett, S. (2001). Knowing in practice: Re-conceptualising vocational expertise. Learning and Instruction, 11, 431-452.

Billett, S. (2011). Vocational education: Purposes, traditions and prospects. New York: Springer.

Black, P. (2015). Formative assessment - An optimistic but incomplete vision. Assessment in Education: Principles, Policy \& Practice, 22(1), 161-177.

Blikstad-Balas, M., \& Sørvik, G. O. (2015). Researching literacy in context: Using video analysis to explore school literacies. Literacy, 49(3), 140-148.

Chugh, S., \& Hancock, P. (2009). Networks of aestheticization: The architecture, artefacts and embodiment of hairdressing salons. Work, Employment and Society, 23(3), 460-476.

Cohen, R. L. (2010). When it pays to be friendly: Employment relationships and emotional labour in hairstyling. The Sociological Review, 58(2), 197-218.

Duranti, A. (1997). Linguistic anthropology. New York: Cambridge University Press.

Ekström, A. (2012). Instructional work in textile craft: Studies in interaction, embodiment and the making of objects. Thesis, Stockholm: Stockholm University.

Ekström, A. (2013). Epistemic positioning and frameworks for participation: Learning to assess objects of craft in teacher education. Learning, Culture and Social Interaction, 2(4), 277-292.

Ekström, A., \& Lindwall, O. (2014). To follow the materials: The detection, diagnosis and correction of mistakes in craft education. In M. Neville, P. Haddington, T. Heinemann, \& M. Rauniomaa (Eds.), Interacting with objects: Language, materiality and social activity (pp. 227-247). Amsterdam: John Benjamins Publishing Company.

Filliettaz, L. (2011). Asking questions...getting answers: A sociopragmatic approach to vocational training interaction. Pragmatics and Society, 2(2), 234-259.

Gåfvels, C. (2016). Vision and embodied knowing: The making of floral design. Vocations and Learning, 9 , 133-149.

Garfinkel, H. (1967). Studies in ethnomethodology. Englewood cliffs: Prentice-Hall.

Goffman, E. (1981). Forms of talk. Pennsylvania: University of Pennsylvania Press.

Goffman, E. (1982). The interaction order. American Sociological Review, 48(1), 1-17.

Goodwin, C. (1994). Professional vision. American Anthropologist, 96(3), 606-633.

Goodwin, C. (1997). The blackness of black: Color categories as situated practice. In B. Resnick, R. Säljö, C. Pontecorvo, \& B. Burge (Eds.), Discourse, tools and reasoning: Essays on situated cognition (pp. 111140). Berlin: Springer.

Goodwin, C. (2000). Talk and embodiment within situated human interaction. Journal of Pragmatics, 32(10), 1489-1522.

Goodwin, C. (2001). Practices of seeing visual analysis: An ethnomethodological approach. In I. T. Van Leeuwen \& C. Jewitt (Eds.), Handbook of visual analysis (pp. 157-182). London: Sage.

Goodwin, C. (2003). Pointing as situated practice. In S. Kita (Ed.), Pointing: Where language, culture and cognition meet (pp. 217-241). Mahwah: Lawrence Erlbaum Associates. 
Goodwin, C. (2006). Interactive footing. In E. Holt \& R. Clift (Eds.), Reporting talk: Reported speech in interaction (pp. 16-46). Cambridge: Cambridge University Press.

Goodwin, C. (2010). Multimodality in human interaction. CAL, 8(2), 85-98.

Goodwin, C. (2013). The co-operative, transformative organization of human action and knowledge. Journal of Pragmatics, 46, 8-23.

Goodwin, C., \& Goodwin, M. H. (1987). Concurrent operations on talk: Notes on the interactive organization of assessments. Pragmatics, 1(1), 1-54.

Goodwin, C., \& Goodwin, M. H. (1992). Assessment and the construction of context. In A. Duranti \& C. Goodwin (Eds.), Rethinking context: Language as an interactive phenomenon (pp. 147-189). Cambridge: Cambridge University Press.

Heitink, M. C., Van der Kleij, F. M., Veldkamp, B. P., Schildkamp, K., \& Kippers, W. B. (2015). A systematic review of prerequisites for implementing assessment for learning in classroom practice. Educational Research Review, 17, 50-62.

Heritage, J. (2005). Conversation analysis and institutional talk. In K. L. Fitch \& R. E. Sanders (Eds.), Handbook of language and social interaction (pp. 103-147). Mahwah: Lawrence Erlbaum Associates.

Heusdens, W. T., Bakker, A., Baartman, L. K. J., \& De Bruijn, E. (2016). Contextualising vocational knowledge: A theoretical framework and illustrations from culinary education. Vocations and Learning, 9, 151-165.

Holmes, H. (2015). Transient craft: Reclaiming the contemporary craft worker. Work, Employment and Society, 29(3), 479-495.

Horlacher, A. S. (2017). Vous coupez quand même pas trop hein: Quand la cliente conteste ou prévient une action du coiffeur. In: L. Mondada \& S. Keel (Eds.), Participation et asymmetries dans l'interaction institutionelle. Cahiers de la Nouvelle Europe Collection du Centre Interuniversitaire d'Études Hongroises et Finlandaises. $\mathrm{N}^{\circ} 23$. L'Harmattan.

Hutchins, E. (2006). The distributed cognition perspective on human interaction. In N. J. Enfield \& S. C. Levinson (Eds.), Roots of human sociality: Culture, cognition and interaction (pp. 375-398). Oxford: Berg.

Jefferson, G. (1984). On the organization of laughter in talk about troubles. In J. M. Atkinson \& J. Heritage (Eds.), Structures of social action: Studies in conversation analysis (pp. 346-369). Cambridge: Cambridge University Press.

Jefferson, G. (2004). Glossary of transcript symbols with an introduction. In G. H. Lerner (Ed.), Conversation analysis: Studies from the first generation (pp. 13-31). Amsterdam: John Benjamins Publishing Company.

Kilbrink, N., \& Bjurulf, V. (2012). Transfer of knowledge in technical vocational education: A narrative study in Swedish upper secondary school. International Journal of Technology and Design Education, 23(3), 519-535. https://doi.org/10.1007/s10798-012-9201-0.

Klope, E. (2015). I skuggan av ett yrke. Om gymnasieelevers identitetsskapande på hantverksprogrammets frisör. Licentiatuppsats i didaktik. Stockholms universitet.

Koole, T., \& Elbers, E. (2014). Responsiveness in teacher explanations: A conversation analytical perspective on scaffolding. Linguistics and Education, 26, 57-69.

Lindsay, J. (2004). Gender and class in the lives of young hairdressers: From serious to spectacular. Journal of Youth Studies, 7(3), 259-277.

Lindström, A., \& Sorjonen, A. L. (2012). Affiliation in conversation. In J. Sidnell \& T. Stivers (Eds.), The handbook of conversation analysis (pp. 350-369). Hoboken: Blackwell Publishing.

Lymer, G. (2013). Assessing the realization of intention: The case of architectural education. Human Studies, $36,533-563$.

McMurtrie, R. J. (2010). Bobbing for power: An exploration into the modality of hair. Visual Communication, 9(4), 399-424.

Merry, S., Price, M., Carless, D., \& Taras, M. (2013). Conclusions and reflections. In S. Merry, M. Price, D. Carless, \& M. Taras (Eds.), Reconceptualising feedback in higher education (pp. 204-209). London: Routledge.

Mondada, L. (2007). Commentary: Transcript variations and the indexicality of transcribing practices. Discourse Studies, 9(6), 809-821.

Mondada, L. (2009). The embodied and Negociated production of assessments in instructional actions. Research on Language and Social Interaction, 42(4), 329-361.

Öhman, A. (2015). Cykler och loopar i Salongen. En studie av återkoppling i frisörklassrummet [Cycles and loops in the Salon. A study of feedback in the hairdressing classroom]. Licentiate dissertation. Karlstad: Karlstad University. 
Öhman, A. (2016). Kameraanvändning i videoobservation [Camera use in video observation]. KAPET Karlstads Universitets Pedagogiska Tidskrift, 12(1), 75-85.

Öhman, A., \& Tanner, M. (2017). Creating space for students' concerns: Embodied feedback practices in hairdressing education. Learning, Culture and Social Interaction. https://doi.org/10.1016/j. lcsi.2017.04.005.

Oshima, S. (2014). Achieving consensus through professionalized head nods: The role of nodding in service encounters in Japan. International. Journal of Business Communication, 51(1), 31-57.

Pomerantz, A. (1984). Agreeing and disagreeing with assessments: Some features of preferred/dispreferred turn shapes. In J. M. Atkinson \& J. Heritage (Eds.), Structures of social action: Studies in conversation analysis (pp. 57-101). Cambridge: Cambridge University Press.

Price, M., Handley, K., O’Donovan, B., Rust, C., \& Millar, J. (2013). Assessment feedback: An agenda for change. In S. Merry, M. Price, D. Carless, \& M. Taras (Eds.), Reconceptualising feedback in higher education: Developing dialogue with students (pp. 41-53). London: Routledge.

Sacks, H., Schegloff, E. A., \& Jefferson, G. (1974). A simplest systematics for the organization of turn-taking for conversation. Language, 5(4), 696-735.

Sadler, R. (2010). Beyond feedback: Developing student capability in complex appraisal. Assessment and Evaluation in Higher Education, 35, 535-550.

Sadler, R. (2013). Opening up feedback: Teaching learners to see. In S. Merry, M. Price, D. Carless, \& M. Taras (Eds.), Reconceptualising feedback in higher education (pp. 54-63). London: Routledge.

Schegloff, E. A. (2007). Sequence organization in interaction. New York: Cambridge University Press.

Schön, D. A. (1983). The reflective practitioner. How professionals think in action. New York: Basic Books.

Skovholt, K. (2017). Anatomy of a teacher-student feedback encounter. Teacher and Teacher Education, 69, 142-153.

Tanggaard, L. (2013). The socio-materiality of creativity. Culture and Psychology, 19(1), 20-32.

Tanggaard, L. (2014a). A situated model of creativity. European Educational Research Journal, 13(1), 107116.

Tanggaard, L. (2014b). Fooling around: Creative learning pathways. Charlotte: Information Age Publishing, Inc..

Taras, M. (2013). Feedback on feedback: Uncrossing wires across sectors. In S. Merry, M. Price, D. Carless, \& M. Taras (Eds.), Reconceptualising feedback in higher education: Developing dialogue with students (pp. 30-40). London: Routledge.

Tyson, R. (2014). Aesthetic bildung in vocational education: The biographical case of bookbinding master Wolfgang B. And his apprenticeship. Vocations and Learning, 7, 345-364.

Yeadon-Lee, T., Jewson, N., Felstead, A., Fuller, A., \& Unwin, L. (2011). Bringing in the customers: Regulation, discretion and customer service narratives in upmarket hair salons. International Journal of interdisciplinary Social Sciences, 6(3), 101-114.

Zemel, A., \& Koschmann, T. (2014). Put your finger right here: Learnability and instructed experience. Discourse Studies, 16(2), 163-183.

Anna Öhman PhD in pedagogical work with research interest in assessment and feedback practices. 